\title{
Comunicação e educação na (re)construção imagética de um Nordeste plural
}

\author{
Communication and education in the (re)construction of a pluralistic \\ Northeast
}

\author{
Deborah Susane Sampaio Sousa Lima - Universidade Tuiutí do Paraná (UTP) | Curitiba | \\ PR | Brasil | E-mail: dsusane@gmail.com
}

João Eudes Portela de Sousa - Universidade Tuiutí do Paraná (UTP) | Curitiba | PR | Brasil | E-mail: joaoportelas@gmail.com

Antonia Nilene Portela de Sousa- Universidade Estadual Vale do Acaraú (UVA) | Sobral | CE | Brasil | E-mail: nileneportela@yahoo.com.br

Mônica Cristine Fort- Universidade Tuiutí do Paraná (UTP) | Curitiba | PR | Brasil | E-mail: monica.fort@yahoo.com.br

Resumo: A pesquisa aborda como a construção imagética do Nordeste contribui para o estabelecimento de estereótipos fortalecidos no meio social por elementos apresentados em narrativas audiovisuais e o papel da escola nos processos de (re)construção desses estigmas. Para tanto, são analisados fatores históricos da constituição desses discursos, no Brasil, considerando as formas caricatas e a propagação simbólica acerca da imagem de uma nordestinidade única e homogênea. Isso tudo, observando como o sistema representacional simbólico - que vai além das divisões geográficas em que os sujeitos estão inseridos - apresenta as raízes nordestinas anacrônicas, frequentemente aproximadas do lugar-comum icônico e distanciadas da hipermodernidade e dos ambientes tecnologizados, assim, a pesquisa traz reflexões sobre como os espaços educativos podem se apropriar dessas produções a fim de (re)apresentar o Nordeste como espaço múltiplo e plural, em prol de uma compreensão holística dos sujeitos.

Palavras-chave: Produções audiovisuais. Nordeste. Identidade. Educação.

Abstract: The research deals with how the Northeast's imaging construction contributes to the strengthened stereotypes in the social environment by the elements presented in the audiovisual narratives and the educational role of the school in the processes of (re)construction of these stigmas. Historical factors of the constitution of these discourses in Brazil are analyzed, considering the caricature forms and the symbolic propagation about the image of a unique and homogeneous Northeastern, observing how the symbolic representational system - which goes beyond the geographical divisions in which the subjects are inserted - presents the anachronistic Northeastern roots, often approximated to the iconic commonplace and distanced from hypermodernity and technologized environments. The research brings reflections on how educational spaces can be adequate for these productions, in order to (re) present the Northeast as multiple space, in favor of a holistic understanding of the subjects.

Keywords: Audiovisual productions. Northeast. Identity. Education.

DOI: http://dx.doi.org/10.22484/2177-5788.2018v44n1p91-108

Recebido em maio 2018. $\quad$ Aprovado em maio de 2018. 


\section{Introdução}

O olhar sobre o Nordeste padece de (re)leituras sobre as representações estabelecidas diante de relações de poder inseridas no universo social, cultural e educacional. Assim, os conceitos sobre nação e região são compreendidos a partir de denominações revestidas de conceitos prévios sobre a formação das identidades de um povo. Nesse sentido, o ambiente educacional encontra, no meio audiovisual, ambiente propício para análises e orientações sobre esses enlaces.

Sabendo-se que nenhuma cultura é una nem mesmo apartada das outras, é possível dizer que ela se forma dentro de um complexo e derivado arcabouço de identidades sociais. Logo, compreender essa lógica é algo denso, de tal modo que falar em região como modo de delimitar um povo é analisar diversos fatores, para além tão somente das questões geográficas.

Portanto, para se abordar a região Nordeste, como referência de um povo, é preciso ter cuidado para não ancorar os fundamentos condutores dessas definições em perspectivas meramente espaciais. Albuquerque Júnior (2011) trata de sinuosidades que envolvem a formação dessas significações, incluindo fatores políticos e econômicos.

A noção de região, antes de remeter à geografia remete uma noção fiscal, administrativa, militar (vem de regere, comandar). Longe de nos aproximar de uma divisão natural do espaço ou mesmo de um recorte do espaço econômico ou de produção, a região se liga diretamente às relações de poder e sua espacialização; ela remete a uma visão estratégica do espaço ao seu esquadrinhamento, ao seu recorte e à sua análise, que produz saber. Ela é uma noção que nos envia a um espaço sob domínio, comandado. Ela remete, em última instância, a regio (rei). Ela nos põe diante de uma política de saber, de um recorte espacial das relações de poder. Pode-se dizer que ela é um ponto de concentração de relações que procuram traçar uma linha divisória entre elas e o vasto campo do diagrama de forças operantes num dado espaço. [...] A região é produto de uma batalha, é uma segmentação surgida no espaço dos litigantes. As regiões são aproveitamentos estratégicos diferenciados do espaço. Na luta pela posse do espaço ele se fraciona, se divide em quinhões diferentes para os diversos vencedores e vencidos; assim, a região é o botim de uma guerra. (ALBUQUERQUE JÚNIOR, 2011, p. 36, grifos originais). 
Na perspectiva de Albuquerque Júnior (2011), a região do Nordeste brasileiro é descrita como sendo uma "invenção política", com o intuito de dividir e definir fronteiras, separando cada uma delas em denominações específicas, diante de um recorte feito na geografia do país, que pode ser atribuído a interesses econômicos, sociais e políticos.

Até os primeiros anos do século $X X$, o Nordeste, tal como enxergado hoje, sequer existia, pelo que havia um Brasil dividido em apenas duas regiões: Norte e Sul. Somente entre as décadas de 1920 e 1930 que se começou a utilizar o termo Nordeste para definir a região que antes fazia parte do eixo Norte do país, tanto nos sentidos historiográficos quando geográficos.

\begin{abstract}
No século 19, a Geografia nasce no Brasil vinculada à História e tem como função desenvolver o conhecimento sistemático sobre o território, para estabelecer as bases da construção da nacionalidade. No início do século 20, a primeira divisão regional do Brasil toma por base as diferenças naturais. Mais do que uma tradição naturalista da Geografia nesse período, parece que os olhos dos brasileiros responsáveis pelo "desenho" do território nacional só são capazes de perceber as diferenças das paisagens desenhadas pela natureza. Reconhecer outras diferenças significaria abalar o mito consagrado da unidade territorial como suporte da unidade política e da coesão social do nacionalismo. (ALBUQUERQUE JÚNIOR, 2011, p. 39).
\end{abstract}

Portanto, esse espaço geográfico intitulado de Nordeste - de múltiplas e marcantes características - tomou forma associado à região dominada pelo clima seco, de solo rachado e de vegetação comprometida. Razão pela qual se iniciou uma busca por auxílios governamentais, inclusive mediante apoio de institutos de obras contra a seca, tanto das esferas federais quanto estaduais.

De fato, à época, a necessidade emergida de definição de um formato específico para delimitar estruturalmente a região configurava uma alternativa para se buscar objetivamente políticas públicas em torno dos problemas que dificultavam a vida das comunidades locais. Com isso, passouse a utilizar o termo Nordeste para se referir a essa região do país. 
O Nordeste é pesquisado, ensinado, administrado e pronunciado de certos modos a não romper com o feixe imagético e discursivo que o sustenta, realimentando o poder das forças que o introduziu na cultura brasileira. (ALBUQUERQUE JÚNIOR, 2011, p. 40).

Com os desdobramentos das definições acerca do Nordeste brasileiro e as consequentes militâncias em torno dessa região, em meados da década de 1920, surgiu um movimento encabeçado pelo estudioso Gilberto Freire de naturalidade nordestina - conhecido como Movimento Regionalista e Tradicionalista, tendo sido peça importante na formação do Centro Regionalista do Nordeste.

O movimento teve relevante importância na difusão das manifestações culturais da região, sendo espaço inovador na busca pela valorização das tradições nordestinas, criado sob a proposta do fortalecimento da memória coletiva e da identidade regionalista. Para além da seca, esse cenário fomentou as discussões históricas e sociais da representatividade do Nordeste para o Brasil.

Diante de uma história de luta em prol da preservação da identidade de um povo, a apropriação dos veículos de comunicação pelos públicos - em especial por meio dos recursos audiovisuais da contemporaneidade - traz questionamentos acerca da noção de realidade e de permanência dos conceitos que são disseminados em sociedade.

Desse modo, este artigo busca compreender em que medida a educação pode contribuir para intensificar ou desmistificar as construções históricas e sociais a respeito do Nordeste, valendo-se de análises sobre produtos audiovisuais em ambientes de ensino. A pesquisa traz, portanto, reflexões e provocações sobre como os ambientes educacionais podem se valer de elementos do audiovisual para apresentar os diversos olhares sobre os contextos históricos que formam a imagem e a identidade de um povo, em especial o Nordeste. 


\section{Contextualizando o Nordeste}

A simbologia que permeia o imaginário dos sujeitos sobre o Nordeste, em torno do sertão e do sofrimento, é parte de um universo de construções representativas influenciadas historicamente por elementos como literatura, canções e teledramaturgia. Por meio de produtos audiovisuais, estigmas em torno do "ser nordestino" foram particularmente fortalecidos com o movimento chamado Cinema de Retomada, momento de grande relevância para o cinema nacional.

Essas representações do Nordeste já vinham sendo exploradas pelo Cinema Novo, pelo que os primeiros filmes traziam personagens nordestinos nas conhecidas chanchadas (gênero popular de humor ingênuo), colocandoos dentro de formatos alegóricos, exóticos e estereotipados. Eram retirantes de capacidade cognitiva comprometida, em paus-de-arara e ao estilo cangaceiro - figuras rotuladas de caipiras do agreste.

Assim, das características disseminadas, a construção de um Nordeste específico nos cinemas esteve bastante vinculada ao ambiente do sertão, configurado como: "Região afastada dos centros urbanos. [...] Zona situada no Polígono das Secas, em que predomina uma agricultura de subsistência, bem como modestos rebanhos" (OLIVEIRA, 1987, p. 508).

Representações em torno desse formato tomaram corpo e estenderamse das telas do cinema para a teledramaturgia brasileira. Assim, as narrativas televisivas - de significativa audiência e apelo popular - perpetuaram essa visão de um universo atrasado, de subcultura, habitado por sujeitos carentes de instrução, fato que vai de encontro ao apregoado por Bhabha (2013, p. 21): "a representação da diferença não pode ser lida apressadamente como o reflexo de traços culturais ou étnicos preestabelecidos, inscritos na lápide fixa da tradição".

Diante desse modelo da linguagem do cinema e da teledramaturgia, houve um enraizamento do imaginário coletivo a respeito do sujeito do Nordeste. A diversidade de contextos sociais desaparece mesmo em meio a 
um universo significativo de personagens. Um legado que não demonstra os modos de vida, os diversos lugares, a vasta geografia nordestina, ainda carente de ser explorada e (re)apresentada aos públicos.

\begin{abstract}
Não tendo uma produção imagética capaz de se autorreferenciar, o cinema recorrerá a imagens e enunciados cristalizados sobre o país, sobretudo pelo romance, para produzir o efeito de verossimilhança desejado, para que o público tenha referências anteriores e possa identificar de que realidade o filme está falando. Os filmes com temática nordestina, por exemplo, quando não são adaptações para o cinema de romances produzidos pela geração de trinta, buscarão nestes romances suas imagens e enunciados mais consagrados, com exceção apenas da produção de Glauber Rocha e outros filmes isolados do Cinema Novo, que procurarão criar uma imagem própria para esta região do Brasil. (ALBUQUERQUE JÚNIOR, 2011, p. 297).
\end{abstract}

Convém observar que identidades regionais são construídas por representações e simbologias operadas em determinados meios. A identidade cultural de um povo é, portanto, o resultado de discursos e construções de sentidos revelados socialmente, de modo que o Nordeste, bem como o restante do país, acabam sendo construções imagético-discursivas e não meros recortes naturais, políticos ou econômicos. Assim, a região em questão acaba estando em toda parte e em lugar nenhum,

[...] porque ele é uma cristalização de estereótipos que são subjetivados como característicos do ser nordestino e do Nordeste. Estereótipos que são operativos, positivos, que instituem uma verdade que se impõe de tal forma, que oblitera a multiplicidade das imagens e das falas regionais, em nome de um feixe limitado de imagens e falas clichês, que são repetidas ad nauseum, seja pelos meios de comunicação, pelas artes, seja pelos próprios habitantes de outras áreas do país e da própria região. (ALBUQUERQUE JÚNIOR, 2011, p. 307).

As categorizações de povos como brasileiros, nordestinos, piauienses etc. são simbologias que têm o intuito de relevar a identidade de um grupo. Mas isso pode não ser algo definitivo, pois não incorpora uma carga genética dos sujeitos. Por outro lado, não são raras as situações em que se incorporam tais características à personalidade, de modo a definir a natureza de tais agrupamentos.

Albuquerque Júnior (2011) incita a desconstrução desses estereótipos na obra A Invenção do Nordeste, em que apresenta argumentos para a 
abstração da imagem dos nordestinos do campo do natural, fixo e imutável, mostrando suas características múltiplas e as perspectivas dos vários Nordestes, a partir de uma ótica da diversidade dos sujeitos. O autor busca romper com a imagem pasteurizada dos nordestinos, ou seja, homogêneos, de características e personalidades similares tão somente pelo fato de fazerem parte de uma mesma região do país. Para tanto, incentiva a se pensar um Nordeste diferente do solidificado especialmente pelos veículos audiovisuais. O pensamento ecoa em obras de outros autores, como Queiroz (2012, p. 6):

Pensar o Nordeste a partir do prisma contemporâneo das inevitáveis conexões com o mundo, desconstruindo um conceito sedimentado no reforço às tradições que consolidam o pensamento dominante e dominador é, no mínimo, falar do cotidiano e das relações que se estabelecem através das "integrações", conceito chave para a sociedade moderna.

Notadamente, as representações se fortalecem no processo de sedução do espectador, habitando o imaginário social com a apropriação de narrativas que constroem estereótipos a partir da ótica dos entes codificadores (produtores de conteúdo). Aos decodificadores (públicos), a mensagem é enviada dentro de formatos e técnicas que conduzem suas percepções sobre o que é apresentado.

[...] as diversas formas de comunicação, cinema, literatura, teatro, pintura, música, produção acadêmica, poesia são exemplos de linguagens que não apenas representam o real, como instituem 0 mesmo. Enquanto alguns propuseram fórmulas de alterações das realidades sócio-ambientais nordestinas, para resgatá-las de certa condição de atraso ou subdesenvolvimento, outros cantavam a tristeza da seca e suas consequências, como a partida dessa região sofrida. (MARTINELLO, 2011, p. 214).

Considerando que o Nordeste é composto de nove estados, com suas múltiplas particularidades - incluindo a infinidade de sotaques presentes em um mesmo domínio - é imprescindível discutir os modos como suas 
representações vêm sendo estabelecidas. Os usos de modelos e arquétipos ${ }^{1}$ que delimitam o "ser nordestino" parece ainda perpetuar a imagem de clássicos, como os apresentados por Euclides da Cunha (1973), na obra Os Sertões:

É o homem permanentemente fatigado. [...] Entretanto, toda esta aparência de cansaço ilude. Nada é mais surpreendedor do que vê-la desaparecer de improviso. Naquela organização combalida operamse, em segundos, transmutações completas. Basta o aparecimento de qualquer incidente exigindo-lhe 0 desencadear das energias adormecidas. O homem transfigura-se. Empertiga-se, estadeando novos relevos, novas linhas na estatura e no gesto; e a cabeça firmase-Ihe, alta, sobre os ombros possantes aclarada pelo olhar desassombrado e forte; e corrigem-se-lhe, prestes, numa descarga nervosa instantânea, todos os efeitos do relaxamento habitual dos órgãos; e da figura vulgar do tabaréu canhestro reponta, inesperadamente, o aspecto dominador de um titã acobreado e potente, num desdobramento surpreendente de força e agilidade extraordinárias. (CUNHA, 1973, p. 128-129).

Seja no teatro, cinema, literatura, televisão, música ou em outros gêneros narrativos, a construção da imagem que permeia o universo social a produção de sentidos - tem influência direta nas visões de mundo que incorporam a cultura. Nesse sentido, é importante ater-se ao fato de que o Nordeste deve ser ressignificado, com vistas à interrupção de fluxos impositivos e reiterados de imagens padronizadas de seus povos.

\section{(Re)configurando o Nordeste}

Não! Você não me impediu de ser feliz! Nunca jamais bateu a porta em meu nariz! Ninguém é gente! Nordeste é uma ficção! Nordeste nunca houve! Não! Eu não sou do lugar dos esquecidos! Não sou da nação dos condenados! Não sou do sertão dos ofendidos! Você sabe bem: Conheço o meu lugar!

BELCHIOR, 1979

${ }^{1} \mathrm{O}$ termo alude a algo que se estabelece no imaginário coletivo, sendo construído por um conjunto de imagens predominantes, que são repassadas ao longo do tempo e armazenadas socialmente como apresentadas reiteradamente. 
Historicamente, a formação do Nordeste como região específica tem origem nas necessidades de angariar políticas públicas voltadas para a região. Entretanto, as representações sobre as regiões brasileiras devem ser observadas diante de uma perspectiva complexa: devem ser estudadas como um sistema que vai além das divisões geográficas e econômicas que encaixam esses lugares em denominações específicas.

Nessa perspectiva, é imprescindível a contribuição da escola na análise de produtos audiovisuais como material pedagógico, uma vez que retratam a identidade imagética da compreensão sobre o Nordeste, a partir da ótica do que é valorado pelo senso comum. Portanto, a inserção desses produtos no ambiente educacional pode elevar discussões sobre o que "se vê" e o que "realmente é" a região Nordeste.

Devemos lembrar, por exemplo, segundo Sodré (2001), como a televisão - assim como a cultura de massa - é pedagógica. Ela ensina por meio de sua própria linguagem: imagens em movimento, sons correspondentes a ações captadas, cenários (ambientes) onde essas ações se desenvolvem, efeitos de iluminação e provocação de movimentos de câmera. E fala a milhares de pessoas, por meio de uma programação que reúne informação, educação, entretenimento, cultura. Narrativas audiovisuais acabam situando fatos em determinadas épocas e reconstroem realidades histórico-sociais "suas estruturas, como uma totalidade em constante mudança" (OSTERMANN, 2006, p. 11).

Assim, ao repetir inúmeras vezes, em diferentes narrativas dispostas em uma grade de programação televisiva, por exemplo, reforça-se a imagem com frequência caricata de sujeitos de diferentes regiões. Os estudos do Albuquerque Júnior (2011) possibilitam compreender a formação do Nordeste como um "lugar criado", ou seja, como uma invenção político-social, a fim de prover delimitações objetivas dos espaços.

O espaço não preexiste a uma sociedade que o encarna. É através das práticas que estes recortes permanecem ou mudam de identidade, que dão lugar à diferença; é nelas que as totalidades se fracionam, que as partes não se mostram desde sempre comprometidas com o 
todo, sendo este todo uma invenção a partir deste fragmento, no qual o heterogêneo e o descontínuo aparecem como homogêneo e contínuo, em que o espaço é um quadro definido por algumas pinceladas. (ALBUQUERQUE JÚNIOR, 2011, p. 35).

De fato, as regiões não nascem prontas, não sendo, portanto previamente estabelecidas, sequer permanecendo imutáveis às definições que Ihes são postas. Logo, as relações constituídas nesses espaços - ditos e caracterizados a partir das supostas diferenças entre uns e outros - se constroem diante do diagnóstico de suas diversidades, quem sejam sociais, econômicas ou culturais.

Assim, o enquadramento de uma região e, consequentemente de um povo, a partir de sua limitação geográfica - como comumente incide sobre os produtos audiovisuais, a exemplo de novelas que representam o sujeito nordestino - trazem uma falsa apresentação e homogenizam os atributos e as qualidades dos que dela fazem parte.

Diante disso, é possível dizer que a gramática que envolve os produtos audiovisuais contribui para a disseminação das produções simbólicas, sendo responsável também pela produção de sentidos nos sujeitos, devendo ser interpretada e discutida nas escolas. As imagens em movimento, os sons relativos às imagens captadas, os cenários onde as ações se desenvolvem, os efeitos de iluminação, as indumentárias dos personagens, tudo isso educa e conduz a algum entendimento.

Por vezes, as representações equivocadas - especialmente do Nordeste, objeto deste estudo - acabam multiplicando preconceitos. Conforme menciona Martín-Barbero (2011, p. 130): "[...] necessitamos de uma escola na qual aprender a ler signifique aprender a distinguir, a tornar evidente, a ponderar, a escolher onde e como se fortalecem os preconceitos ou se renovam as concepções que temos sobre política, família, cultura e sexualidade". "Nossos territórios existenciais são imagéticos. Eles nos chegam e são subjetivados por meio da educação, dos contatos sociais, dos 
hábitos, ou seja, da cultura, que nos faz pensar o real como totalizações abstratas" (ALBUQUERQUE JÚNIOR, 2011, p. 38).

As "falsas realidades" são fortemente reafirmadas pelos produtos audiovisuais. Logo, para se compreender melhor as relações que envolvem os entes de cada região, é preciso apartar-se desse olhar previamente estabelecido sobre as práticas e os comportamentos dos povos, vez que a influência das mídias sobre o olhar "do outro" tende a corromper e a conduzir as percepções mediante uma experiência mediada.

A construção imagética do Nordeste em narrativas audiovisuais acaba por camuflar a verdadeira identidade de seu povo, considerando que as barreiras geográficas estabelecidas sobre a região definem perfis e papéis sociais homogêneos, sem considerar a multiplicidade cultural. Os meandros históricos, como apresentado anteriormente, demonstram a existência dos vários interesses que conduzem as definições de cada região.

Nas produções audiovisuais - como o cinema e a televisão -, narrativas são construídas sob uma gramática específica, incorporada pelos elementos que compõem o seu texto. Esses recursos transmitem informações, ideias e significados que giram em torno de uma produção simbólica, influenciando os espectadores na formação de sentidos, como sugere Duarte (2002, p. 5152):

O significado cultural de um filme (ou de um conjunto deles) é sempre constituído no contexto em que ele é visto e/ou produzido. Filmes não são eventos culturais autônomos, é sempre a partir dos mitos, crenças, valores e práticas sociais das diferentes culturas que narrativas orais, escritas ou audiovisuais ganham sentido.

É nesse diapasão que insurgem as visões pré-conceituadas, exatamente com o estabelecimento de estereótipos sobre o "ser nordestino", baseados em traduções que, por vezes, divergem das realidades locais e regionais, também dos seus costumes e hábitos e dos seus processos de formação e de inserção na história, sendo o audiovisual um mecanismo para fortalecer esses estigmas. Naturalmente, não se trata apenas do cinema, as 
telenovelas, os programas humorísticos, os telejornais também apresentam a representação do nordestino em um contexto nacional.

Por isso, usar esses recursos como objetos didáticos, é imprescindível para contribuir para as discussões e as análises sobre as abordagens do "outro", propondo um olhar crítico dos modos de se enxergar e propagar as diferenças. Apropriando-se das ideias de Silva (2010), é possível perceber como a produção audiovisual elabora significados e influencia as percepções de mundo dos espectadores,

[...] o cinema constitui-se em uma matriz social singular de percepção, elaboração e transmissão de saberes e fazeres, possibilitando distintas formas de apreensão, compreensão e representação do mundo. Nesses termos, enquanto uma modalidade integrante do conhecimento humano, o cinema orienta e explica percursos individuais e grupais formados em ambiências em que a imagem em movimento constitui e possibilita aprendizados que passam a compor o estoque de experiências da sociedade. (SILVA, 2010, p. 161-162).

Apesar do autor se referir especificamente ao cinema, consideram-se as observações quanto à narrativa audiovisual. Portanto, tendo em vista que os discursos narrativos nessas produções são sempre mediados, ou seja, estão fincados sob a ótica de um autor ou diretor, a partir de suas experiências, a interpretação desses objetos em sala de aula traz reflexões acerca da construção imagética dos sujeitos em uma sociedade.

Tendo como pressuposto que a codificação empreendida no audiovisual pode influenciar a decodificação dos elementos pelos públicos, pode-se dizer que o processo de

[...] ver filmes, discuti-los, interpretá-los é uma via para ultrapassar as nossas arraigadas posturas etnocêntricas e avaliações preconceituosas, construindo um conhecimento descentrado e escapando às posturas 'naturalizantes' do senso comum. (TEIXEIRA, 2006, p. 8).

Isso justifica a necessidade de trabalhar essas temáticas em sala de aula, facilitando o processo de ensino-aprendizagem, vez que o uso de recursos audiovisuais favorece o desenvolvimento do olhar crítico dos educandos, tendo o professor como mediador das (des)construções simbólicas que são apresentadas em torno da naturalização do Nordeste, ou 
seja, da tendência de se tornar comum as representações que são postas nessas narrativas.

Isso posto e considerando que os ritos de produção e de recepção dos objetos comunicacionais não seguem uma linearidade predeterminada, podese dizer que a troca de mensagens entre emissores e receptores, apesar de planejada, traz desdobramentos em seus resultados. Por trás de cada elemento audiovisual, há contextos em que foram envolvidos e analisá-los contribui para a compreensão acerca dos aspectos histórico-sociais da realidade.

Considere-se, inicialmente, que os objetos das práticas comunicacionais são compostos por "significados e mensagens, sob a forma de signos-veículo de um tipo específico, organizados, como qualquer forma de comunicação ou linguagem, pela operação de códigos dentro da corrente sintagmática de um discurso" (HALL, 2003, p. 387-388). Nota-se que os ritos de produção e de circulação das informações são enraizados por simbolismos no meio audiovisual - ou seja, pela formação dos sentidos - que precisam ser discutidos, especialmente nas escolas, dado o fato de serem ambientes propícios ao desenvolvimento intelectual e social dos cidadãos.

A importância do envolvimento com o imaginário dos alunos, muito embora não seja competência absoluta dessas entidades, é fundamental para o distanciamento de visões estereotipadas de mundo. E pode interferir no processo de interpretação do conteúdo recebido - decodificação para Hall (2003) -, o que vai definir o significado de cada mensagem é a formação social e cultural de quem a recebe.

Segundo Hall (2003), os sujeitos podem ter uma interpretação hegemônica - recebendo e interpretando a mensagem de forma prédeterminada pelos meios de comunicação -; uma interpretação opositora de não aceitar e se opor à mensagem recebida -; ou uma interpretação negociada, entre o ponto de vista hegemônico e opositor, conforme o assunto, levando em consideração suas próprias experiências e seus contatos 
sociais. Para tanto, o diálogo nas instituições escolares é fundamental para essa negociação na interpretação das mensagens recebidas.

\begin{abstract}
Os aparatos, relações e práticas de produção, aparecem, assim, num certo momento (o nome da 'produção/circulação'), sob a forma de veículos simbólicos constituídos dentro de regras de 'linguagem'. É nessa forma discursiva que a circulação do 'produto' se realiza. [...] Mas é sob a forma discursiva que a circulação do produto se realiza, bem como sua distribuição para diferentes audiências. Uma vez concluído, o discurso deve então ser traduzido - transformado de novo - em práticas sociais, para que o circuito ao mesmo tempo se complete e produza efeitos. Se nenhum 'sentido' é apreendido, não pode haver 'consumo'. Se o sentido não é articulado em prática, ele não tem efeito. (HALL, 2003, p. 388, grifo original).
\end{abstract}

Contudo, o conjunto que se constrói dentro dessa variedade de atividades é o que revela o que se compreende por identidade social, ou seja, a identidade de um determinado povo. A reincidência da apresentação do "ser nordestino" como sujeito de um só corpo, homogêneo e sem peculiaridades é prática notadamente aplicada nos cinemas e nas televisões brasileiras, produzindo um só Nordeste, distanciando os públicos dos "vários Nordestes" que efetivamente existem.

[...] como a produção deste lugar e de seus habitantes não pode ser explicada se nos colocamos apenas numa perspectiva econômica ou política. [...] da produção histórica de um espaço social e afetivo, ao longo de muitas décadas, a partir de diferentes discursas que lhe atribuírem determinadas características físicas e o que investiram de inúmeros atributos morais, culturais, simbólicos, sexualizantes, às vezes enervantes. (ALBUQUERQUE JÚNIOR, 2011, p. 14).

Conhecer os "verdadeiros Nordestes" (plural) é papel integrador dos sujeitos em sociedade, vez que são personagens múltiplos da história e das memórias do Brasil. Portanto, cabe também à escola dissecar o que são as representações colocadas nos meios audiovisuais. "É mister reconhecer que a análise de filmes pode ter um desdobramento para a própria teoria educacional à medida que sugere eixos constitutivos de uma educação dos sentidos" (LOUREIRO, 2006, p.14).

Ao invés do nordestino humilde, com fala cantante e retirante em busca de oportunidades nas cidades grandes, existem nordestinos fortes, intelectuais e empreendedores que contribuem para o desenvolvimento de REU, Sorocaba, SP, v. 44, n. 1, p. 91 - 108, jun. 2018 
uma nação que precisam ser enxergados como realmente são. O levantamento dessas discussões na escola dá sentido à proposta da formação holística, moral e cidadã às salas de aulas, desconstruindo esses estigmas.

A representação una e imutável de nordestinos é argumento presente nas produções simbólicas que solidificam o imaginário brasileiro, por vezes, sem considerar as novas referências desses povos. Ao contrário, em frequente (re)construção no campo da representação, esses sujeitos se mostram heterogêneos e com subjetividades, características e identidades múltiplas.

Albuquerque Júnior (2015) reforça que a imagem dos nordestinos apreendida socialmente é deslocada da realidade e, como advém da visão de terceiros que não vivenciam suas práticas culturais, padece de critérios de verossimilhança. Logo, a noção que se tem sobre esses povos "é uma voz arrogante que se dá o direito de dizer o que é o outro em poucas palavras". (ALBUQUERQUE JÚNIOR, 2015, p. 30).

O pesquisador completa que o "estereótipo nasce de uma caracterização grosseira e indiscriminada do grupo estranho" (ALBUQUERQUE JÚNIOR, 2015, p. 20), o que dificulta ainda a chance de se falar do "outro" com propriedade e veracidade. Ora, apesar de parecer fácil abordar a temática da regionalidade a partir das noções de senso comum e de geografia, isso envolve complexas estruturas histórico-sócio-culturais, muitas vezes já corrompidas por imagens solidificadas pelos veículos de comunicação.

Neste paradigma, cabe à escola buscar reordenar as estruturas ideológicas a respeito das regiões que envolvem o Brasil plural e o Nordeste compreendido por seus diversos estados, seus diferentes sotaques e suas variadas culturas, cuja amplitude vai muito além do que as delimitações espaciais estabelecidas e apresentadas reiteradamente nos produtos audiovisuais. 
"O Nordeste não é um fato inerte na natureza. [...] O Nordeste é uma espacialidade fundada historicamente, originada por uma tradição de pensamento, uma imagística e textos que Ihe deram realidade e presença", (ALBUQUERQUE JÚNIOR, 2011, p. 79). Os sujeitos nordestinos inserem-se em manifestações e em representações de diversas culturas brasileiras que devem ser discutidas e lembradas como modo de instruir a respeito dessas diferenças.

\section{Considerações finais}

O Nordeste concebido no meio audiovisual brasileiro pode ser visto como fruto de construções simbólicas resultantes de processos históricosociais experimentados ao longo dos anos. Notadamente, a constituição da identidade regional desse povo é parte das interferências das relações de poder travadas, entre outras questões, por meandros políticos e geográficos, o que impacta no processo de representação estabelecido nos produtos audiovisuais.

A padronização de um Nordeste pode ser medida pelas narrativas em torno dos personagens regionalistas que dão lugar a perfis já enquadrados em determinados modelos. No campo do cinema, por exemplo, frequentemente tem-se a identificação de um espaço geográfico limitado pela miséria, com predominância da seca e carente de desenvolvimento. $\mathrm{Na}$ teledramaturgia, os sujeitos nordestinos são recorrentemente personificados como retirantes, ou de pouca escolaridade ou, ainda, detentores de empregos secundários.

Ocorre que compreender o "ser nordestino" sob uma perspectiva determinista - na qual o lugar determina a identidade do sujeito - sugere um afastamento do universo que envolve esses personagens, contribuindo para a propagação de estereótipos. Isso desloca os elementos do audiovisual da realidade, vez que não considera as multiplicidades, as diversidades de elementos que formam o Nordeste. 
Do exposto, é possível apreender que as construções audiovisuais perpetuam objetos simbólicos carregados de "falsas verdades", muitas vezes fortalecendo a imagem descontextualizada sobre o outro. Isso repercute na limitação da visão sobre as regiões, sobre as culturas e sobre as identidades de um povo - que não são fixas nem naturalmente impostas por fatores geográficos - de tal maneira que a sociedade incorpora como absoluta.

Dada a função da escola - entidade revestida da qualidade de disseminadora do conhecimento em sua completude - deve-se buscar integrar metodologias de aprendizagem que incentivem o olhar crítico dos cidadãos. Para tanto, é imprescindível que se aproprie do que está posto, das ferramentas de propagação de informações (em que os produtos audiovisuais se inserem) como meios de inserir em sala de aula discussões temáticas que visem ao ensino integrador dos sujeitos na sociedade.

Como proposta de suprimento das lacunas do campo audiovisual nas (re)apresentações do Nordeste, a escola tem papel fundamental para a apresentação das pluralidades identitária e cultural existentes na região nordestina. Levar o ensino prático a partir de análises críticas desses produtos oportuniza o contrassenso, o contraditório e o estudo dos paradoxos sociais, tão importantes para a formação dos sujeitos.

Apesar da fixação de ideologias sociais comprometidas pela força das narrativas apresentadas nos veículos audiovisuais, a ressignificação imagética dos verdadeiros Nordestes (plural) pode ser almejada com a contrapartida da escola. A cristalização de fenômenos e significados construídos sobre o ethos dos sujeitos nordestinos convive com desafios que devem ser enfrentados para se buscar a inserção de novos olhares sobre o "outro".

\section{Referências}

ALBUQUERQUE JÚNIOR, Durval Muniz de. A invenção do Nordeste. 5 ed. São Paulo: Cortez, 2011. 
ALBUQUERQUE JÚNIOR. Preconceito contra a origem de lugar: as fronteiras da discórdia. 2 ed. São Paulo: Cortez, 2015.

BELCHIOR, Antônio Carlos. Conheço o meu lugar: era uma vez um homem e o seu tempo. Wea, 1979.

BHABHA, Homi. O local da cultura. Belo Horizonte: UFMG, 2013.

CUNHA, Euclides da. Os sertões. São Paulo: Cultrix, 1973.

DUARTE, Rosália. Cinema \& educação. Belo Horizonte: Autêntica, 2002.

HALL, Stuart. Codificação/decodificação. In: HALL, Stuart; SOVIK, Liv (Org.). Da diáspora: identidades e mediações culturais. Belo Horizonte: Editora UFMG, 2003. p. 387-404.

LOUREIRO, Robson. Da teoria crítica de adorno ao cinema crítico de Kluge: educação, história e estética. Tese de Doutorado, 295 p., 2006. Programa de Pós-Graduação em Educação. Universidade Federal de Santa Catarina, Florianópolis, 2006. Disponível em:

<https://repositorio.ufsc.br/handle/123456789/88741>. Acesso em: 20 set. 2017.

MARTÍN-BARBERO, Jesus. Desafios culturais: da comunicação à educomunicação. In: CITELLI, Adilson Odair; COSTA, Maria Cristina Castilho. Educomunicação: construindo uma nova área de conhecimento. São Paulo: Paulinas, 2011.

MARTINELLO, André Souza. Territórios e fronteiras, Cuiabá, v. 5, n. 1, p. 222-215, jul-dez. 2011. Disponível em:

<http://www.ppghis.com/territorios\&fronteiras/index.php/v03n02/article/vi ewFile/115/108>. Acesso em: 18 fev. 2018.

OLIVEIRA, Cêurio de. Dicionário cartográfico. 3 ed. Rio de Janeiro: IBGE, 1987.

OSTERMANN, Nilse Wink. Filmes contam história. 3. ed. Porto Alegre: Movimento, 2006.

QUEIROZ, André (Org.). Arte e pensamento: a reinvenção do Nordeste. Fortaleza: Serviço Social do Comércio, 2012.

SILVA, Veruska Anaricema Santos da. Memória e cultura: cinema e aprendizado de cineclubistas baianos dos anos 1950. Dissertação (Mestrado). Universidade Estadual do Sudoeste da Bahia, 162 p., 2010. Vitória da Conquista: UESB, 2010. Disponível em:

$<$ http://www2.uesb.br/ppg/ppgmls/wpcontent/uploads/2017/06/Silva_VAS.pdf>. Acesso em: 18 set. 2017.

SODRÉ, Muniz. A televisão é uma forma de vida. Entrevista concedida a Paulo Cirne Caldas. Famecos, Porto Alegre, n. 16, p. 18-35, dez. 2001.

TEIXEIRA, Inês Assunção de Castro. A diversidade cultural vai ao cinema. Belo Horizonte: Autêntica, 2006. 